\title{
Intercultural Competence Formation with Linguodidactical Approach for Students at Non-Language Universities
}

\author{
Gayane Oganesovna Petrosyan ${ }^{1, *}$, Irina Stepanovna Bashmakova ${ }^{2}$, Elena Alexandrovna Danilina ${ }^{3}$, \\ Indiana Ivanovna Kazieva ${ }^{1}$ \\ ${ }^{1}$ Department of Foreign Languages, Faculty of Economics, RUDN University, Miklukho-Maklaya Street, 6, Moscow, 117197, Russia \\ ${ }^{2}$ Department of Foreign Languages, Russian State University named after A.N. Kosygin, Sadovnicheskaya Street, 33, Moscow, \\ 117997, Russia \\ ${ }^{3}$ Department of Foreign Languages, Faculty "International Business School and Global Economy", Plekhanov Russian University of \\ Economics, Stremyanny Lane, 28, Moscow, 117997, Russia
}

Received October 22, 2020; Revised December 15, 2020; Accepted January 27, 2021

\section{Cite This Paper in the following Citation Styles}

(a): [1] Gayane Oganesovna Petrosyan, Irina Stepanovna Bashmakova, Elena Alexandrovna Danilina, Indiana Ivanovna Kazieva , "Intercultural Competence Formation with Linguodidactical Approach for Students at Non-Language Universities," Universal Journal of Educational Research, Vol. 9, No. 1, pp. 253 - 260, 2021. DOI: 10.13189/ujer.2021.090127.

(b): Gayane Oganesovna Petrosyan, Irina Stepanovna Bashmakova, Elena Alexandrovna Danilina, Indiana Ivanovna Kazieva (2021). Intercultural Competence Formation with Linguodidactical Approach for Students at Non-Language Universities. Universal Journal of Educational Research, 9(1), 253 - 260. DOI: 10.13189/ujer.2021.090127.

Copyright $\bigcirc 2021$ by authors, all rights reserved. Authors agree that this article remains permanently open access under the terms of the Creative Commons Attribution License 4.0 International License

\begin{abstract}
The article is devoted to the main aspects of the $\mathrm{x}$ approach application for the intercultural competence formation for students. The article discusses the specific pedagogical principles of the linguodidactic approach, which are necessary for the formation of intercultural competence in the linguodidactic education model. The purpose of the article is to present the data obtained in the course of an empirical study, establishing the linguodidactic approach effectiveness in the intercultural competence formation among students of non-linguistic universities. The research materials were questionnaires of three groups of the 3rd course and one control group of students at RUDN University. The general sample consisted of 45 people (each group consisted of 15 students). The period of the empirical research coincided in time with the annual students' practice, which made it possible to use information, related to the main specialization of students, as the basis for the application of the linguodidactic approach to teaching English. The methodology of our empirical research is based on a systematic approach and includes a group of general scientific methods (analysis, synthesis, deduction, induction), as well as a group of special methods: content
\end{abstract}

analysis of scientific literature on the research topic, the method of sociological questioning (survey); as well as a method for analyzing statistical data. Based on the data obtained, the author of the article concludes that the linguodidactic approach to teaching English for students of non-linguistic specialties proves its effectiveness due to the connection between language practice and the formation of intercultural competence.

Keywords Linguodidactics, Communicative Competence, Intercultural competence, English, Teaching Methods, Didactic Principles

\section{Introduction}

The research topic relevance is due to the fact that the problem of the communicative competence formation "as the main component of the competence for the professional qualifications of a modern specialist", as stated in the Federal State Standard of Higher Education, is mainly discussed in the mainstream of communicative 
and especially cultural-communicative approaches in domestic and foreign teaching methods [1, p. 562].

Mastering intercultural competence, as one of the components of communicative competence, is one of the most important results of teaching English, since without this result, the communication process in a foreign language is absolutely impossible. At the same time, the process of monitoring teaching in higher educational institutions showed that students do not have the most important skills of intercultural communicative competence, cannot consistently and convincingly express their point of view, replacing the logic arguments with unfounded statements; and also do not know special vocabulary and cannot actively participate in communication on professional topics $[2$, p. 106]. The problem of the formation of intercultural competence is especially acute among students during the period of mass distance learning $[3,4]$.

So, the formation of intercultural competence should be considered as a purposeful process that requires new approaches. In this regard, the question of the linguodidactic approach implementation for the formation of intercultural competence among students of non-linguistic universities has a particular relevance.

In this context, it should be noted, that didactics as a science studies the laws operating in the field of its subject, analyzes the dependencies that determine the course and learning process results, determines the methods, organizational forms and means that ensure the implementation of the planned goals and objectives. On the whole, the didactics has two main functions:

- theoretical (mainly diagnostic);

- practical (normative, instrumental).

Linguodidactics is a relatively young scientific discipline that emerged in the second half of the 20th century. Linguodidactics has been designed to determine the basic laws of the process of the foreign language teaching, in order to create an objective scientific basis for assessing the teaching methods' effectiveness and their further improvement. Linguodidactics, being an integrative science, is designed to give both a description of the language acquisition mechanisms and the specifics of managing these mechanisms in an educational setting.

Thus, the linguodidactic approach provides for the interaction of several independent and, at the same time, interrelated scientific disciplines: methodology, linguistics, pedagogy, psychology, psycholinguistics. The linguodidactic approach represents the linguistic base of teaching foreign languages in conjunction with the listed scientific disciplines.

In the methodology field of teaching a language, linguodidactics performs the following functions:

1) Scientific-theoretical function (study of the process of teaching a language);

2) Constructive and modeling function (improvement, transformation of the educational process);
3) Integrative function (combining the scientific achievements of philosophers, linguists, teachers, psychologists, methodologists, specialists in communication theory and computer science in order to reliably substantiate the language learning process).

The historiography of the studied issue is quite extensive and includes the works of both domestic and foreign authors. At the same time, among Russian studies, it is necessary to highlight the works by such authors as M. Aschi [5], F. Aufa [6], O. Bogush [7], I. Chorna [8], D. D'Arcy Nell [9], devoted to the general issues of the linguodidactic approach application to teaching and issues of the linguodidactic model of teaching at the university.

In foreign historiography, works of a practical orientation prevail. Among this kind of empirical research, the works by O.V. Gura [10], M. Hansson [11] are very useful. Specific methods for the intercultural competence formation are considered in the studies by J.F. Jabborova [1], N.F. Koryakovtseva [2], E.N. Malyuga et al. [12-15], M. Oftobkhon [3], E.V. Savitskaya [16].

Generally, most researchers determine the effectiveness of the linguodidactic approach as a result of selection, the use of various elements in training and its organizational forms. The intercultural competence development is necessary for the implementation in students' professional activities, which allows them to improve the correspondence of skills and abilities. Nevertheless, despite a fairly extensive historiography of research, in foreign and domestic science, at the moment there is a lack of works that would compare the effectiveness of the linguodidactic approach in different groups of students of non-linguistic universities.

\section{Materials and Methods}

The research materials were questionnaires of three groups of the 3rd course and one control group of full-time students at RUDN University.

The general sample consisted of 45 people (each group consisted of 15 students). The empirical research period coincided in time with the annual practice of students, which made it possible to use information, related to the main specialization of students, as the basis for the application of the linguodidactic approach to teaching English.

The methodology of our empirical research is based on a systematic approach and includes a group of general scientific methods (analysis, synthesis, deduction, induction), as well as a group of special methods: content analysis of scientific literature on the research topic, the method of sociological questioning (survey); as well as a method for analyzing statistical data.

Revealing the linguodidactic approach effectiveness in teaching English was carried out on the basis of 4 criteria: 
1) the level of students' motivation to learn;

2) the level of independence in working with educational materials;

3) the level of vocabulary activation;

4) the level of communication activity.

For each of their criteria, a questionnaire was compiled, consisting of 10 questions: questions to identify the level of motivation; questions to identify the level of independence; questions regarding the level of vocabulary activation, as well as a questionnaire with questions to identify the level of communicative activity.

Each of the listed criteria was assessed on a 10-point scale, where 1-3 points correspond to a low level of compliance with the criterion; 4-6 - medium level; 7-10 points correspond to a high level of compliance with the criterion. The control group method was also used to compare the results. The data obtained in the course of empirical research were processed by us in the Neural Designer software, used in statistical analysis for advanced descriptive, diagnostic and prescriptive analytics. For each of the questionnaires, the program calculated the average score for each students' group, on the basis of which diagrams were drawn up based on the questionnaire results.

The teaching methodology included such types of work as: project activities with the participation of native speakers of English; conducting virtual presentations by students in English (in the format of presentations in the studied specialty), as well as individual types of independent work. The empirical study was conducted from 1 to 28 February 2020.

\section{Results}

As a result of the survey in the group of respondents students of the graphic faculty, the following data were obtained (Figure 1).

As can be seen from the data presented in Figure 1, in this group of respondents, after a series of classes using the linguodidactic approach, students who took part in the empirical study had a high level of all four effectiveness criteria.

Data on Figure 1 show that, in comparison with the control group, in which the classes were conducted according to the traditional method of thematic study of grammar, the motivation of the respondents doubled, as well as the other indicators (independence in working with educational materials, activation of vocabulary and an active communicative position). In our opinion, such results are associated precisely with the linguodidactic approach to teaching, since its basic principles were used when working with the experimental group.

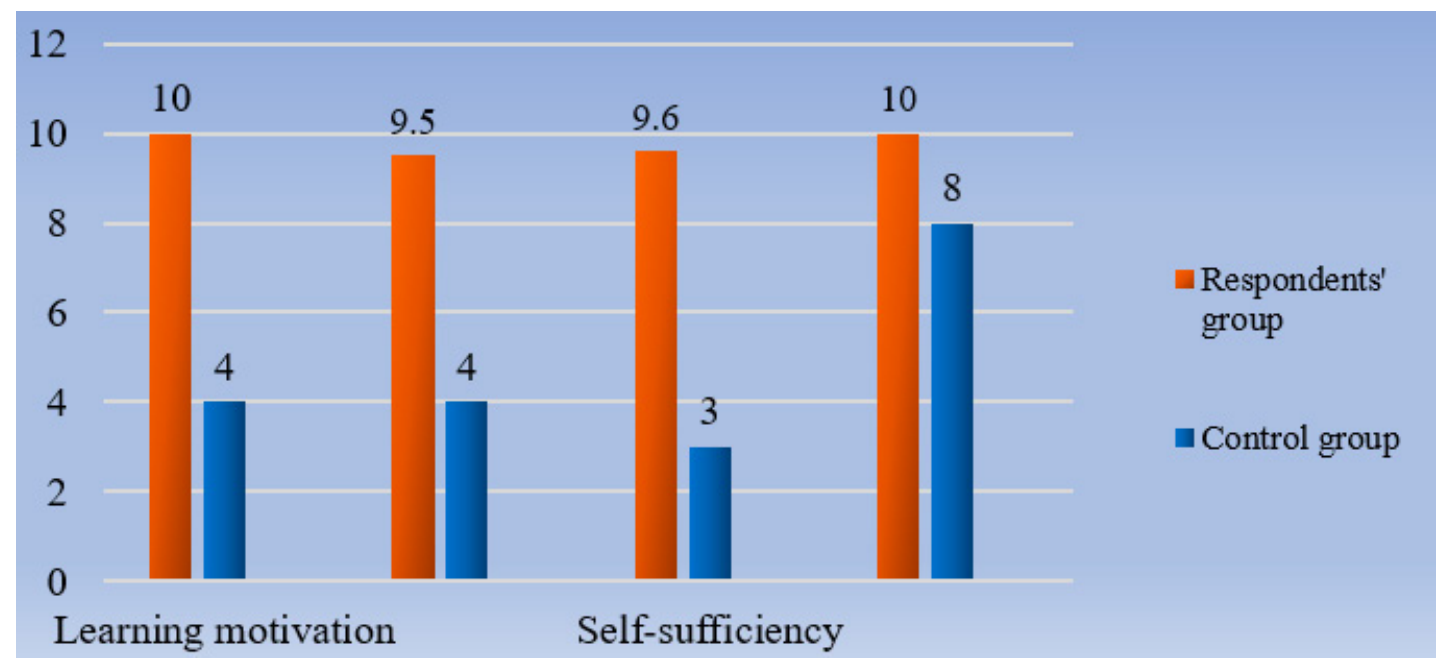

Figure 1. The effectiveness of a cultural approach in teaching English (compiled by the author using the program Neural Designer analytics) 


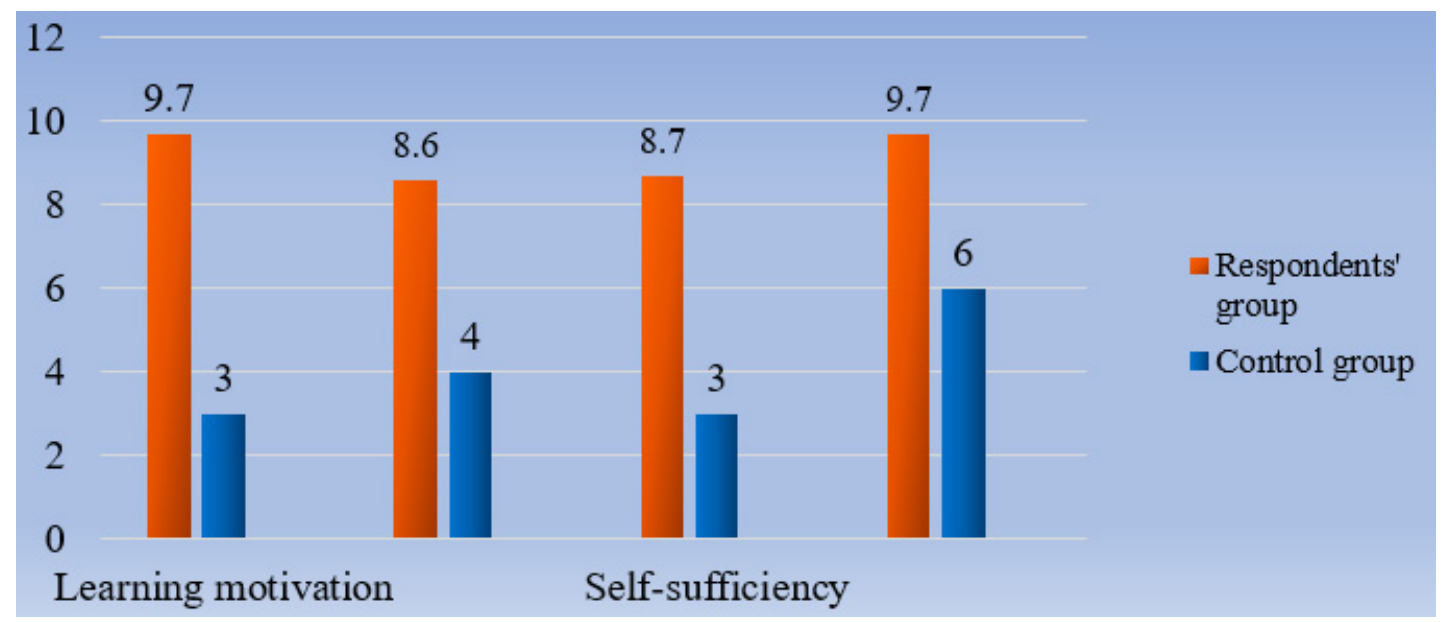

Figure 2. The effectiveness of the cultural approach in teaching English (compiled by the author using the program Neural Designer analytics)

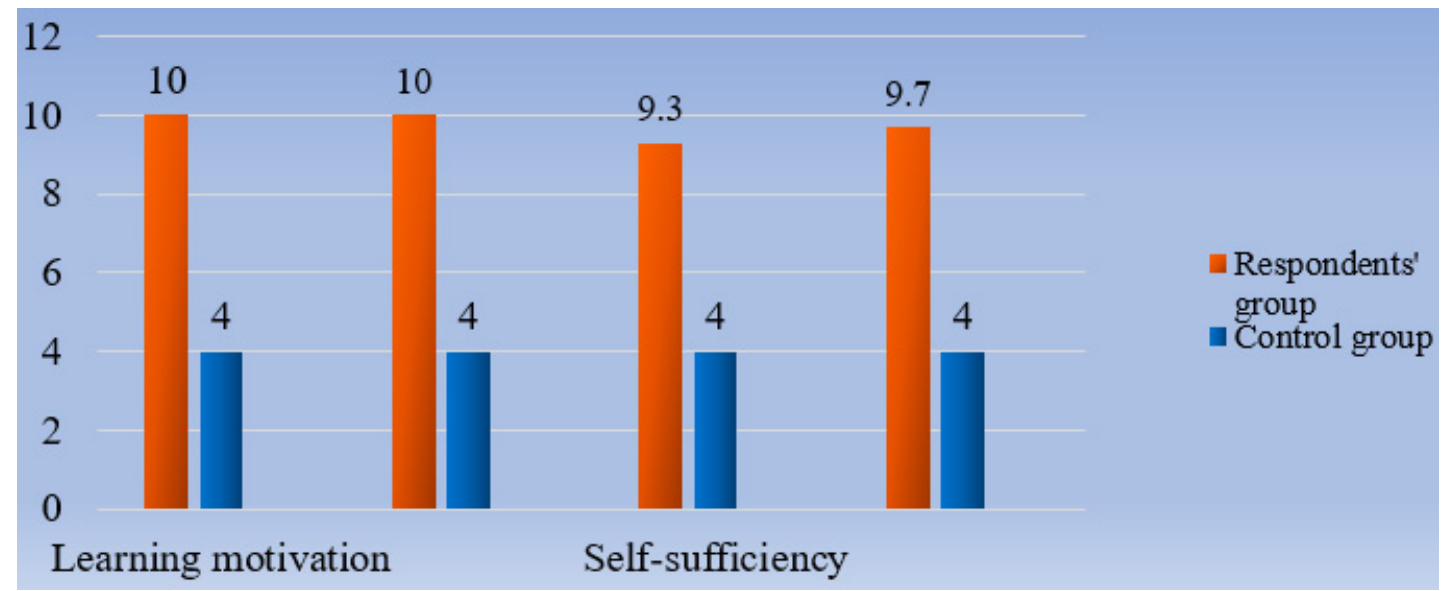

Figure 3. The effectiveness of the cultural approach in teaching English (compiled by the author using the program Neural Designer analytics)

Similar results were obtained following the survey in the second group of respondents, which are presented in comparison with the control group (Figure 2).

Compared to the control group, in the group of respondents, one can note a significant increase in motivation to learn English, an increase in independence in working with educational materials, as well as an activation of vocabulary to almost the maximum level. In our opinion, such results are associated with the fact that students - participants in the empirical research, showed a particular interest in classes in English on issues related to their main professional specialization.

According to the data presented in Figure 2, the students, who took part in the empirical study also showed a high level of all four criteria for the effectiveness of the linguodidactic approach to teaching.

Sufficiently high results were also achieved in the third group of respondents, in comparison with the control group (Figure 3).

As far as can be seen from the data obtained, the students, who took part in the empirical study, also showed an increase in the level of motivation, communication activity, and showed a high level of independence when working with registration materials. An increase in the level of vocabulary activation was also revealed. At the same time, in the control group, in which the classes were conducted according to the traditional method, the indicators of all four criteria for the effectiveness of the linguodidactic approach remained at the average level.

Thus, on the basis of the data obtained, we can conclude that the linguodidactic approach to teaching English for students of non-linguistic specialties proves its effectiveness due to the connection between language practice and the formation of intercultural competence.

Moreover, the students' interest in independent work, the growth of motivation for learning influenced the activation of the passive vocabulary and replenishment of the active vocabulary. The interest shown by students in working in groups with native speakers of English was in fact the main driving factor in teaching English in our empirical study. At the same time, the results we have presented and the conclusions formulated do not claim to be the final truth, since the correlation of linguodidactic methods of teaching English and the use of specific objects of world experience in this process requires 
additional research and verification.

\section{Discussion}

Based on the analysis of existing scientific approaches to teaching English using the linguodidactic approach, the following principles of the intercultural competence formation among students of non-linguistic universities are:

1) Creation of a communicative situation. In the context of linguodidactic learning, the teacher must create a situation that students may face in real life. Unlike the audio-linguistic method of teaching a language, which is based on repetition and exercises, "the linguodidactic approach can leave students in the dark about the result of the exercise, which will vary depending on their reactions and responses" $[1, \mathrm{p}$. 562].

At the same time, it is necessary to apply new situations for each lesson; otherwise, students quickly lose interest, which negatively affects the motivation for learning. The fact is that students' motivation to learn themes from their desire to communicate meaningfully on topics that are meaningful to them. According to N. Pitra, "language is interaction; it is an interpersonal activity that has a clear connection with society. In this light, language learning should consider the use of the communicative function of language in context, both its linguistic context (what is pronounced before and after a given discourse fragment) and its social or situational context (who says, what are the social roles of the speaker, etc.)" [17, p. 126].

2) Creation of a "success situation". According to this principle, the teacher, as a moderator of the learning process, constantly observes the communication students' strategies and can easily determine what communication difficulties each member of the English language group has.

At the same time, the teacher within the framework of linguodidactic training can create new opportunities for self-realization and self-esteem for students who have problems, associated with linguophobia or difficulties in starting contact. The success situation in this case depends on the specific problems of the student and can be created using such well-known pedagogical techniques as project activities, brainstorming, individual presentations and reports at online conferences. The teacher can vary these techniques depending on the goals of creating a "situation of success".

3) Help in solving communication problems. In the context of linguodidactic education, when communicating with native speakers, students may have a problem of "beginning contact", which, without its prompt solution, can lead to such a phenomenon as linguophobia - the fear of speaking a foreign language. To solve this problem using the linguodidactic approach, it is necessary to practice the phatic function of the language, to acquaint students with the speech etiquette of the English language, speech formulas and templates that help to start contact correctly [18]. This principle is necessary for the formation of intercultural competence and in fact, underlies the implementation of this competence: without the skill of starting contact, further communication becomes impossible.

Almost all foreign authors pay attention to the importance of this principle, however, in the real practice of Russian universities within the framework of classical classroom work, special courses of speech etiquette are not read to students (the only exception, perhaps, is the course "Business English") [1, 2, 10,11].

In our opinion, help in solving communication problems is also necessary to increase the students' learning motivation, since, if a person physically experiences the fear of speaking a foreign language, he strives for self-removal from communication and cannot actively participate in general studies. In such a situation, English classes "turn into a real nightmare for a student who suffers from linguophobia" [18, p. 17]. At the same time, if within the framework of classroom work, students may feel embarrassed in recognizing the problems of starting a contact, then the linguodidactic approach allows to build individual consultations in the "student-teacher" mode, and more openly discuss the communicative difficulties that a student has in the process of speaking.

\section{4) The principle of cooperation.}

To create an atmosphere of cooperation in the framework of linguodidactic learning, the teacher should be the coordinator for the students' educational activities, which includes a contribution to the lesson at a high emotional level, the direction of the learning motivation to find interesting forms of group work. To applicate this principle, the teacher can use the "collaboration learning" method, which is widely used by foreign universities within the framework of the linguodidactic teaching model. For example, according to Saadet Çina and Mustafa Cem Babadogan, this method allows to use the students' communicative strategies more effectively, project-based teaching method, as well as work in "small groups" [19, p. 73].

5) The principle of trust. This principle of linguodidactics is related to psychology and means the maximum possible confidence in the student's independent work. The more student works independently, looks for information, proves his opinion in a group in the process of dialogue and performs creative tasks by means of pedagogical mentoring, the more vividly his communicative abilities are revealed [19, p. 74].

It should be noted that it is abilities, as well as 
communication skills, that underlie the intercultural competence formation. They are the result of the experience of communication between people. At the end of the lesson, the student can conduct personal reflection, analyze the acquired knowledge and skills on an emotional level, and make a decision to deepen his intercultural competence. In some foreign studies, for example in the work by N. Sabat [20], a structural-functional model of the intercultural competence formation is presented, within the framework of the linguodidactic approach, which shows all stages of this process, including the search for methodological foundations (principles, concepts), as well as the creation of pedagogical conditions, means and methods of forming this process.

A teacher, applying a linguodidactic approach, is also required to be able to correct all forms of work through organization of methodological support; clearly defined content of students' communicative competence formation; as well as implementation of activities, aimed at the formation of students' communicative competence; a system of conversational interaction between a teacher and students based on the results of their independent work.

6) Work in groups. This principle means the formation of intercultural competence by the methods of group activities. To master intercultural competence, students need to use group work methods that are most effective in the linguodidactic learning model. For example, during the discussion, students think independently and follow the thoughts of a dialogue partner, and also seek information on problematic issues, actively discuss them, and also learn to listen to the opinion of another person without criticism or objection. As a pedagogical technique, the teacher can offer a "brainstorming" session during a discussion; this kind of "pedagogical coaching", according to some foreign researchers, is most effective in group work: students learn not only to establish visual and ethical contact with a communication partner, but also to form communicative competence with the help of specific thematic tasks [21, p. 22].

On the whole, this principle means that students master thematic and professional communication through group learning activities. At the same time, the teacher should carefully monitor the emotional state of students in the process of group communication. It is not always possible to build a detailed dialogue on a given topic. Therefore, the trainer should encourage each participant to discuss verbal and non-verbal methods.

7) Methodology for diagnosing learning outcomes. In the context of linguodidactic approach, a special methodology is needed that allows assessing the work of each student in a group. At the same time, the program for the formation of intercultural competence should be based on the methods of both individual and group work. To implement this pedagogical condition, foreign authors offer the following diagnostic techniques: 1) "Self-control in communication" - Snyder's testing, which involves the distribution of communicative control levels over the gradation of emotional restraint and control of students' communicative behavior when interacting with other participants in online classes [21];2) "how communicative you are" - an adapted technique of R. Ryakhovsky, which allows to quantify the level of a person's sociability [21].

In particular, in the works by R. Schmidt-Fajlik [21], O. Shults [22], G.V. Sorokovykh, I.R. Shafikova [23] on the basis of theoretical sources, criteria have been developed to determine the level of formed intercultural competence among students in the learning process, including motivational, speech and practical criteria; levels of communicative competence: high, medium and low.

These developments, from a methodological point of view, are quite applicable in the practice of Russian universities for the formation of the communicative competence of students at non-language universities in the framework of the linguodidactics learning model [24, p. 8].

Moreover, in our opinion, the use of already developed questionnaires for the diagnosis of learning outcomes with some slight adaptation can be useful for the development of the communication skills of students not only at non-language universities.

8) Changing the role of the teacher. This principle is that the role of the teacher inevitably changes in the distance learning model: from the classic "translator" of ready-made knowledge and controller of completed tasks to the role of moderator, observer and coordinator of the learning process $[25, \mathrm{p}$. 43]. If this condition is not met, then the whole process of learning comes down to performing a huge number of written test tasks for grammar and replenishment of passive vocabulary, which does not allow the formation and development of intercultural communicative competence $[26, \mathrm{p}$. 56]. If this condition is met, within the framework of linguodidactics approach, the teacher speaks less and listens more, "becoming an active assistant in teaching his students, and not checking written assignments" [27, p. 57].

If this principle is met, the teacher issues assignments, since the goal is the "communicative performance" of students, the teacher must step back and observe, sometimes acting as an arbiter or coordinator [28, p. 216]. This approach forms the responsibility of students for completing the assignment. Due to increased responsibility, in turn, students can gain confidence in the use of the target language in general. 
Moreover, according to T.S. Tiutiuma [29], Tran Quoc Thao, Tan Pham [30], students become more responsible leaders of their own learning activities. The article by these authors depicts some problems of communication culture and speech culture. The concepts of "speech culture", as well as "culture of communication", which includes the culture of thinking have been analyzed by providing with examples. Also, in the main part, linguodidactic speech of culture, and accepted rules of behavior in various speech acts of communication are explained by using descriptive analysis method [24, p. 9].

Some researchers also note that for the majority of teachers in Russian universities, this principle of the linguodidactic approach is the most difficult, since its observance requires a fundamental rejection of the classical role of a teacher in the framework of the traditional teaching model [31, p. 63]. At the same time, it is the development of self-sufficiency and a creative approach to the set communicative tasks that contributes to the formation and development of intercultural competence for students at non-linguistic universities.

In our opinion, the above opinions on the effectiveness of the linguodidactic approach, using the example of its basic principles, are fully confirmed by the data of our empirical research.

\section{Conclusions}

The empirical research and analysis of scientific literature allow us to conclude that when building a methodological basis for the formation of intercultural competence, it is necessary to concretize the entire range of linguodidactics principles for the formation of communicative competence, on the one hand, in the aspect of the formation of students' linguistic skills (accumulation of language material), on the other hand, in terms of mastering their specific professional activities, which includes communication skills. Since this study is based on modern foreign methodological developments in the framework of the linguodidactic approach, we can say that such developments are quite applicable to increase professional motivation and creative attitude to the communicative competence of students at non-language universities.

Nevertheless, the theoretical generalizations, put forward by us, cannot claim the status of absolute truth and need verification using a series of empirical studies in the following areas: pedagogical conditions for motivating students using the linguodidactic method; solving communication problems, developing communication skills with native speakers. In this context, a promising area of research is the study of the linguodidactic approach possibilities to teaching English in the framework of the communicative competence formation among students of non-linguistic universities.

\section{Acknowledgements}

This paper has been supported by the RUDN University Strategic Academic Leadership Program.

\section{REFERENCES}

[1] G. F. Jabborova. Linguodidactic Aspects of Phraseology, Theor. Appl. Sci., Vol. 86, No. 6, 561-563, 2020.

[2] N. F. Koryakovtseva. Actual Problems of Linguodidactics: Lecture Course, Izdatelstvo Prospekt LLC, Moscow, 2020.

[3] M. Oftobkhon. Linguodidactic backgrounds of creating video lessons, Acad. An Int. Multidiscip. Res. J., Vol. 10, No. 5, 645-656, 2020.

[4] A. A. Kharkovskaya, I. B. Krivchenko. Conceptual organization of social network discourse (based on FACEBOOK social network), Vopr. Prikl. lingvistiki, Vol. 3, No. 27, 60-77, 2017.

[5] M. Aschi, L. P. Muhammad, N. V. Tatarinova. Intercultural communicatiom as anthropological linguodidactics component, Rudn J. Russ. Foreign Lang. Res. Teach., Vol. 16, No. 2, 143-156, 2018.

[6] F. Aufa. Stereotyping in the Classroom: Promoting Intercultural Communicative Competence in English Language Teaching, Ling. Didakt. J. Bhs. dan Pembelajaran Bhs., Vol. 7, No. 1, 9-16, 2017.

[7] A. Bogush. Methodology- and speech-oriented training of the future Master students majoring in Preschool Education, Sci. Bull. South Ukr. Natl. Pedagog. Univ. named after K D Ushynsky, Vol. 3, No. 128, 9-14, 2019.

[8] I. Chorna. Linguodidactic Model of English Lexical Competence Formation in Written Communication of Prospective Marketers, Sci. Issues Ternopil Volodymyr Hnatiuk Natl. Pedagog. Univ. Ser. Pedagog., Vol. 7, No. 1, 108-113, 2017.

[9] D. D. Nell. English Language Teaching, Ling. Didakt. J. Bhs. dan Pembelajaran Bhs., Vol. 6, No. 4, 57-64, 2017.

[10] V. O. Gura. Features of the Implementation of Linguodidactic Testing in the Process of Learning a Foreign Language, Bull. Kharkov Natl. Automob. Highw. Univ., Vol. 3, 48-55, 2018.

[11] M. Hansson. STEM for English Language Teaching, Int. J. Pedagog. Educ., Vol. 2, 31-46, 2020.

[12] E. N. Malyuga, A. Krouglov, B. Tomalin. Linguo-cultural competence as a cornerstone of translators' performance in the domain of intercultural business communication, XLinguae, Vol. 11, No. 2, 566-582, 2018.

[13] E. Malyuga, D. Maksimova, M. Ivanova. Cognitive and Discoursive Features of Speech Etiquette in Corporate Communication, Int. J. English Linguist., Vol. 9, No. 3, 310-318, 2019.

[14] E. Malyuga, A. Shvets, I. Tikhomirov. Computer-based analysis of business communication language, 2016 SAI 
Computing Conference (SAI), 229-232, 2016.

[15] E. Malyuga, S. Orlova. Teaching Professional English Terminology to Students of Economic Universities, EDULEARN16 Proceedings, 7236-7241, 2016.

[16] E. V. Savitskaya. Interaction of cultural and language competencies in the development of non-native speech skills in educational discourse, Prof. Discourse Commun., Vol. 2, No. 1, 59-71, 2020.

[17] N. Pitra. Foreign Language Discourse in Linguodidactics of Higher Education, Int. Sci. J. Education Sci., Vol. 2(27), No. 1, 125-128, 2019.

[18] H. Rose, N. Galloway. Global Englishes Language Teaching, in Global Englishes for Language Teaching, Cambridge University Press, 3-27, 2019.

[19] S. Cinar, M. C. Babadogan. A comparison with the competencies of English language teaching program, New Trends Issues Proc. Humanit. Soc. Sci., Vol. 5, No. 5, 72-77, 2018.

[20] N. Sabat. Linguodidactic Model of The Process of Formation of Strategic Competence of Future Interpreters, Sci. Issues Ternopil Volodymyr Hnatiuk Natl. Pedagog. Univ. Ser. Pedagog., Vol. 6, No. 1, 63-82, 2019.

[21] R. Schmidt-Fajlik. Interpersonal competence in English language teaching. 2020.

[22] O. E. Shults. Conceptual Approaches and Theoretical Model of The Notion 'Multilingual Giftedness' in Modern Linguodidactic Knowledge, Pedagog. Issues Theory Pract., Vol. 3, No. 1, 147-150, 2018.

[23] G. V. Sorokovykh, I. R. Shafikova. Notion of Professional's Secondary Linguistic Personality in Domestic and Foreign Linguodidactics: Systematic Review, Pedagog. Vopr. Teor. i
Prakt., Vol. 4, 419-424, 2020.

[24] E. Yuzar. Incorporating Communicative Competence in Assessment and English Language Teaching in Multilingual Settings, REiLA J. Res. Innov. Lang., Vol. 2, No. 1, 8-13, 2020.

[25] S. K. Shahzad, J. Hussain, N. Sadaf, S. Sarwat, U. Ghani, R. Saleem. Impact of Virtual Teaching on ESL Learners; Attitudes under Covid-19 Circumstances at Post Graduate Level in Pakistan, English Lang. Teach., Vol. 13, No. 9, 1-9, 2020.

[26] X. Zheng, Y. Gao. Promoting Intercultural Competence in English Language Teaching: A Productive Bilingualism Perspective, in Second Handbook of English Language Teaching, Springer, Cham, 54-58, 2019.

[27] H. Thomas. Mindful English Language Teaching, in International Conference on Mindfulness Asia Pacific, 56-61, 2019

[28] M. O. Voloshko, T. N. Sukhareva. Using the Tandem-Method in English Language Teaching for Developing Intercultural Competence, Soc. - Econ. Phenom. Process., Vol. 10, No. 11, 216-219, 2016.

[29] T. S. Tiutiuma. Typological Occurrences of Syntactical Connection in Word Combinations: Linguistic and Linguodidactic Aspects, Innov. Pedagog., Vol. 2, No. 24, 66-69, 2020.

[30] T. Q. Thao, P. Tan. The importance of intercultural communicative competence in English language teaching and learning., in Innovation and creativity in teaching and learning foreign languages, 23-31, 2017.

[31] Z. K. Uteshova. Linguodidactic Aspect of Communication Culture, Eurasian Union Scientists, Vol. 7, No. 70, 62-64, 2020. 